\title{
AVALIAÇÃO DE PARÂMETROS DE CONSUMO DE COMBUSTÍVEL DO TRITREM NO TRANSPORTE DE MADEIRA ${ }^{1}$
}

\author{
Glauco Lima da Silveira ${ }^{2}$, Carlos Cardoso Machado ${ }^{3}$, Amaury Paulo de Souza ${ }^{3}$, Helio Garcia Leite ${ }^{3}$, Heleno \\ Nascimento dos Santos $^{3}$ e Dalila Campos de Medeiros Fernandes ${ }^{4}$
}

\begin{abstract}
RESUMO - Analisou-se o efeito dos parâmetros marcha lenta, excesso de rotação do motor para valores superiores a $2.000 \mathrm{rpm}$, pontos neutros e velocidades superiores a $80 \mathrm{~km} / \mathrm{h}$, com o objetivo de monitorar o consumo de combustível de veículos de transporte rodoviário de duas transportadoras de madeira (A e B), com base nas informações obtidas de um computador de bordo instalado no cavalo-mecânico LS 2638 da Mercedes-Benz. A marcha lenta foi responsável pelo maior desperdiço de combustível; as transportadoras A e B consumiram 20.122,33 e 18.321,72 L/mês, respectivamente. Ela induziu a um consumo mensal de combustível na ordem de R \$ 19.164,50 (91,32\%) e R \$ 17.449,61 (99,09\%), pois, em média, os motores dos veículos funcionaram 24,47 e 25,79\% do tempo de operação para as transportadoras A e B, respectivamente. O excesso de rotação do motor dos veículos também induziu ao consumo mensal de combustível de $\mathrm{R} \$ 69,45(0,33 \%)$ para a transportadora A e de $\mathrm{R} \$ 155,62$ $(0,88 \%)$ para a transportadora B. O ponto neutro contribuiu com o consumo de combustível em $\mathrm{R} \$ 1.751,73$ $(8,35 \%)$ e $\mathrm{R} \$ 4,80(0,03 \%)$, respectivamente, para as transportadoras A e B. Não foi calculado o consumo relativo ao excesso de velocidade, por não serem conhecidos a faixa de potência, a rotação e o consumo específico associado a cada velocidade. A metodologia usada é específica para o motor OM 457 LA, podendo ser adotada em outros estudos, desde que adaptada às especificações dos motores utilizados; a marcha lenta foi responsável pelo maior consumo de combustível no transporte de madeira, seguida do ponto neutro e do excesso de rotação. No transporte de madeira é possível reduzir significativamente o consumo de combustível em relação à marcha lenta, em virtude do elevado tempo de espera (carregamento, descarregamento, filas e paradas obrigatórias). $\mathrm{O}$ uso do ponto neutro e o excesso de velocidade não economizam combustível e comprometem a segurança. As rotações superiores a 2.000 rpm implicam desperdício de combustível. O ponto de rotação máxima ideal para o motor dos veículos nas condições estudadas está na faixa de $1.700 \mathrm{rpm}$. Um pequeno número de equipes foi responsável pelo elevado número de infrações cometidas. A falta de treinamento dos motoristas contribui para o aumento de consumo de combustível. O cumprimento das normas sobre condução econômica ajuda a reduzir os custos com combustível.
\end{abstract}

Palavras-chave: Consumo de combustível, transporte rodoviário de madeira, controle logístico e computador de bordo.

\section{EVALUATION OF FUEL CONSUMPTION PARAMETERS ON TRITREM WOOD TRANSPORT}

\begin{abstract}
The parameters low gear, excess engine rotation over 2,000 rpm, neutral gear and speed superior to $80 \mathrm{~km} / \mathrm{h}$ were evaluated to monitor fuel consumption of two wood transporters $(A$ and $B)$ using data from a board computer installed on a Mercedes-Benz, LS 2638 model. Low gear increased fuel consumption cost by R\$ $19,164.50$ (91.32\%) and $R \$ 17,449.61$ (99.09\%) per month, since, on average, the vehicle engines functioned about $24.47 \%$ and $25.79 \%$ of the running time for the transporters $A$ and $B$, respectively. Excess engine rotation also increased fuel consumption cost by $R \$ 69.45(0.33 \%)$ and $R \$ 155.62(0.88 \%)$ for the transporters $A$ and $B$, respectively. Neutral Gear contributed to fuel consumption cost of $R \$ 1,751.73(8.35 \%)$ and $R \$ 4.80(0.03 \%)$, respectively, for transporters $A$ and $B$. The methodology used is specific for the OM 457 LA engine, but it could
\end{abstract}

Recebido para publicação em 20.5.2003 e aceito para publicação em 17.2.2004.

2 Eng. Floresal, M.S. em Ciência Florestal - UFV e ex-bolsista da CAPES; ${ }^{3}$ Professor Titular do Dep. de Engenharia Florestal da Universidade Federal de Viçosa - UFV, 36570-000 Viçosa-MG; ${ }^{4}$ Bolsista de Pós-Doutoramento do CNPq. 


\begin{abstract}
be used in other studies, provided some adaptation is made; low gear had the highest fuel consumption in wood transport followed by neutral gear and excess engine rotation. Significant fuel consumption reduction is possible in wood transport in relation to low gear, due to the long waiting time (loading, unloading, lines, and mandatory stops) Neutral gear and excess vehicle speed do not save fuel and compromise safety. Engine rotations superior to 2,000 rpm waste fuel. The ideal maximum rotation point for vehicle engine was about 1,700 rpm. A few teams were accounted responsible for the high number of driving violations. The lack of trained drivers contributed to fuel consumption increase. Compliance to economic driving norms has contributed to fuel cost reduction.
\end{abstract}

Key words: Fuel consumption, wood transport, Tritrem.

\section{INTRODUÇÃO}

Um dos maiores problemas econômicos atualmente relaciona-se ao preço do petróleo e seus derivados, tão consumidos no mundo inteiro e de cujas importações tantos países dependem para sustentar o seu desenvolvimento. Portanto, a busca pelo seu domínio, comandada por grandes potências mundiais, é responsável pelas guerras ocasionadas nos últimos anos, com conseqüentes desequilíbrios na economia mundial e gravíssimos reflexos em nosso país, apesar de este necessitar da importação de apenas cerca de $10 \%$ do petróleo consumido.

No Brasil, o setor de transporte é responsável por quase $50 \%$ do consumo de derivados do petróleo, sendo o óleo diesel o principal combustível utilizado no transporte de cargas e passageiros. Não se esperam, nos próximos 20 anos, alternativas econômicas que, em larga escala, substituam este combustível no setor de transporte. Assim, aumentar a eficiência e a racionalização de seu uso é, acima de tudo, ação estratégica (Guimarães, 2003).

Como as medidas relacionadas aos crescentes aumentos do preço do combustível não sinalizam ter efeito a curto prazo, é fundamental atuar com medidas que envolvam o planejamento e o controle do consumo nas atividades que demandam quantidade elevada de combustível, como o transporte de madeira, sendo o controle dos fatores que levam à eficiência do transporte necessário para evitar situações em que o custo do combustível gasto em função, por exemplo, da distância percorrida seja maior que o custo da carga transportada, o que muitas vezes pode acontecer, em grande parte devido à impossibilidade de aplicação de uma estratégia adequada, que é contornada pelo lucro que se obtém no produto agregado.

Dessa maneira, o planejamento pode ser conceituado, segundo Rocha (1995), como uma função administrativa capaz de definir antecipadamente o que deverá ser feito e que técnicas poderão ser empregadas, onde, quando e por quem, dando ênfase a grandes ou pequenos detalhes, de acordo com a exigência do caso.

Por sua vez, o controle pode ser definido como o ato de fazer com que algo aconteça da forma como foi planejado (Thompson, 1976). Assim, para que se realize um controle é preciso entender claramente os resultados de uma ação em particular, para desta forma determinar se os resultados previstos estão ocorrendo, bem como fazer as mudanças necessárias para atingir os resultados desejados (Dewelt, 1977).

O transporte florestal consiste na movimentação de madeira dos pátios ou das margens das estradas até o local de consumo. No Brasil, pode ser realizado por diversos tipos de veículo, em função da distância de transporte, do volume de madeira a ser deslocado, das condições locais da região, da capacidade de carga do veículo e dos tipos de equipamentos de carregamento e descarregamento (Machado et al., 2000).

A utilização do computador de bordo como ferramenta de controle gerencial tem sido adotada por grandes transportadoras de carga. Ele pode ser descrito como um sistema composto por um equipamento adaptado ao veículo e um conjunto de aplicativos que gerenciam o recebimento e a análise das informações monitoradas no veículo. O resultado desse monitoramento é uma ferramenta para análise e gerenciamento da frota de veículos (Aeroeletrônica, 1997).

A justificativa deste trabalho refere-se aos elevados custos provenientes do consumo de combustível de duas empresas responsáveis pelo transporte rodoviário de madeira, designadas por transportadoras A e B. O objetivo geral foi monitorar o consumo de combustível dos veículos de transporte rodoviário de madeira, utilizando como ferramenta de controle logístico o computador de bordo. Como objetivos específicos podem-se citar: 
estabelecer uma metodologia de estudo de gestão do consumo de combustível em veículos de transporte rodoviário de madeira; quantificar o consumo de combustível em relação aos parâmetros marcha lenta, excesso de rotação e ponto neutro; detectar os parâmetros que mais influenciam o consumo de combustível, apontando alternativas para sua redução; quantificar as ocorrências de ponto neutro, excesso de velocidade e rotação, apontando suas desvantagens; e apresentar uma cartilha para condução econômica do veículo, visando a redução dos custos relacionados ao consumo de combustível.

\section{MATERIAL E MÉTODOS}

\subsection{Local de Estudo}

O estudo foi realizado em uma empresa florestal especializada na produção de celulose de eucalipto, localizada no norte do Estado do Espírito Santo, no município de Aracruz, cuja longitude é $40^{\circ} \mathrm{W}$ e a latitude $19^{\circ} \mathrm{S}$.

As rotas rodoviárias distribuíram-se por três localidades: sul da Bahia (BA), São Mateus (ES) e Aracruz (ES), com predominância de geometria plana e piso asfáltico, abrangidas em sua maioria pela BR 101.

\subsection{Caracterização do Sistema de Transporte}

O transporte foi realizado em regime de três turnos, de 8 horas cada um, operando 24 horas por dia e 365 dias ao ano, o que exigiu uma equipe de três motoristas por veículo. A dinâmica de condução dos veículos das transportadoras A e B com frota analisada foi de $54 \mathrm{e}$ 40 CVCs, respectivamente.

O combustível usado no transporte de madeira foi fornecido pela Aracruz Celulose S.A. O preço do diesel utilizado nos cálculos de custo foi de $\mathrm{R} \$ 0,9524$, que é o valor médio dos meses de setembro a novembro de 2002, período em que as informações foram registradas pelo microcomputador de bordo.

As informações referentes aos dados coletados consistiram de dias de operações diferentes para cada veículo, portanto tornou-se conveniente transformar os dias relativos às operações em uma unidade fixa de tempo, mensal. Assim como os dias de operações foram convertidos em uma unidade-padrão, o tempo das operações foi convertido em minutos, uma vez que o consumo foi expresso nesta unidade.

\subsection{Composição Veicular de Carga (CVC)}

O cavalo-mecânico utilizado em todas as CVCs foi o Mercedes-Benz, modelo LS-2638, com tração 6x4 (Figura 1). Ele possui um motor turbo-alimentado com intercooler, modelo OM-457 LA, com sistema de injeção por gerenciamento eletrônico, que proporciona melhor desempenho. O LS-2638 possui capacidade máxima de tração-técnica (CMT) de 123 toneladas (MERCESBENZ, 2003).

O Tritrem foi o tipo de CVC utilizado no transporte de madeira com capacidade de carga útil média de 52 toneladas. A Figura 2 ilustra um Tritrem carregado com madeira roliça em um pátio industrial.

\subsection{Coleta de Dados}

Foi utilizado o computador de bordo (MB) para monitorar e coletar dados de cada veículo. Os MBs utilizados foram de dois tipos: a) caixa-preta, que funciona sem a intervenção humana, e b) teclado e mostrador, que permitem registrar eventos previamente codificados, controlando as diversas operações do veículo (Figura 3).

\subsection{Velocidade}

Não foi calculado o consumo relativo ao excesso de velocidade, por não se conhecer exatamente a faixa de potência associada a cada rotação, no entanto foi possível detectar que os excessos se deram entre 80 e $90 \mathrm{~km} / \mathrm{h}$, salvo algumas exceções, que ultrapassaram esta faixa.

\subsection{Rotação do Motor}

Considerou-se a rotação do motor de $2.000 \mathrm{rpm}$ como teto, acima do qual foi considerada infração. O relatório do $\mathrm{MB}$ forneceu o tempo em que os veículos excederam o teto de rpm. De acordo com as curvas de desempenho do motor estudado, quando a rotação do motor é de $2.000 \mathrm{rpm}$ o consumo específico é igual a $220 \mathrm{~g} / \mathrm{kWh}$. Utilizando este valor, a densidade do combustível de $850 \mathrm{~g} / \mathrm{L}$ (Barros, 2003) e a potência de $280 \mathrm{~kW}$, obtém-se um consumo de $72,47 \mathrm{~L} / \mathrm{h}$, conforme se segue:

Consumo específico $=\frac{\text { Consumo horário }(L / h) * \text { massa específica }(g / L)}{\operatorname{Potência}(K w)}$

(eq. 1) 


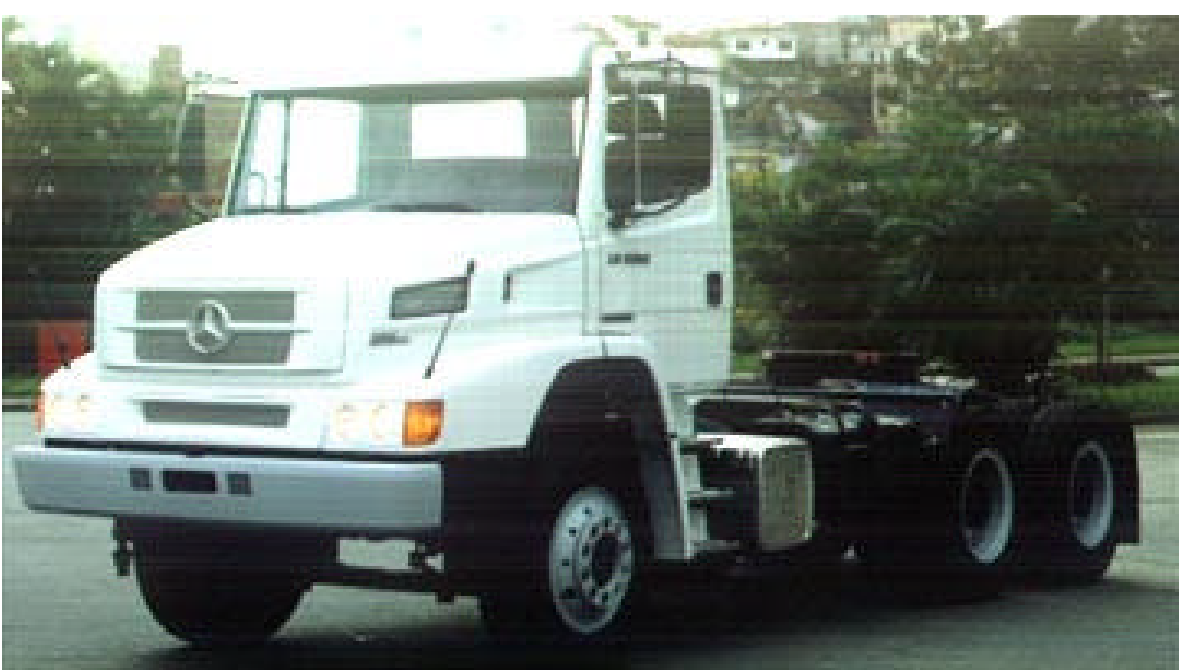

Fonte: Mercedes-Benz (2003).

Figura 1 - Cavalo-mecânico Mercedes-Benz, model o LS-2638.

Figure 1 - Mercedes-Benz, truck-tractor model LS-2638.

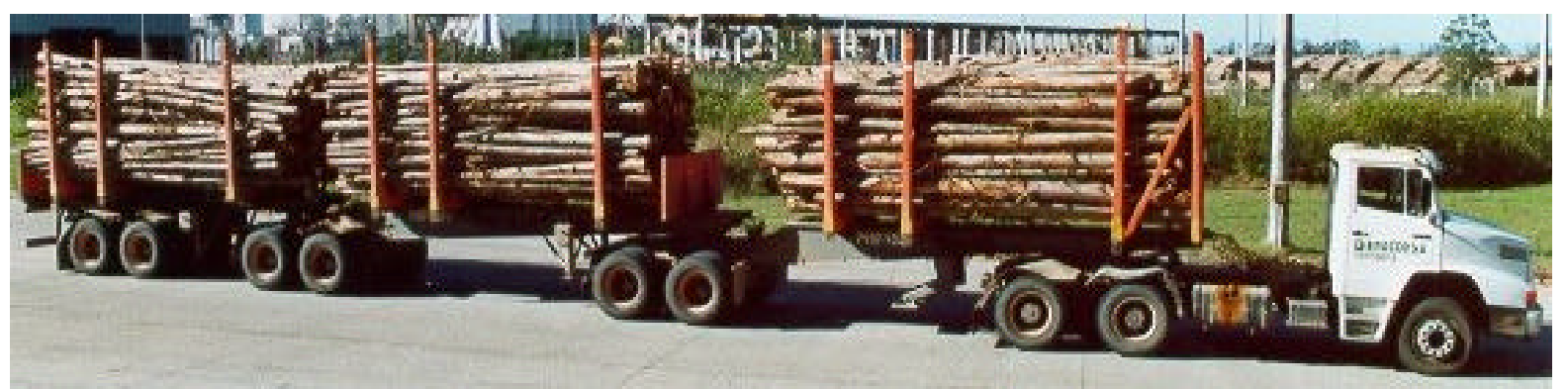

Figura 2 - Tritrem na Aracruz Celulose. Figure 2 - Tritrem in Aracruz Cellulose.

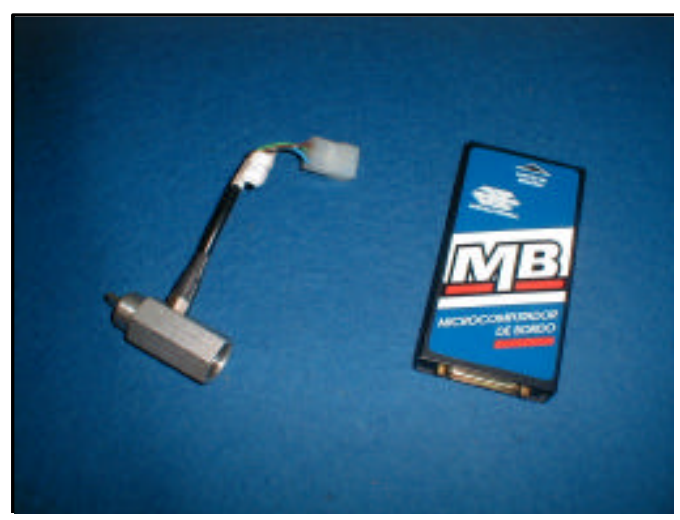

a) Tipo caixa-preta

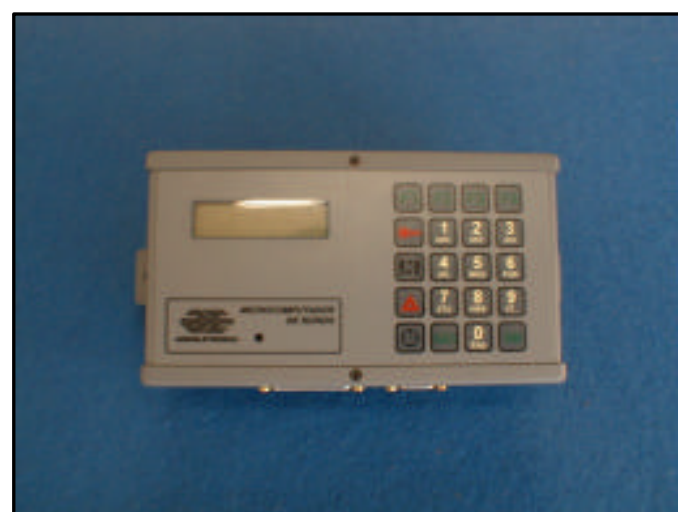

b) Tipo teclado e mostrador.

Figura 3 - Microcomputador de bordo (MB). Figure 3 - Board computer (MB). 
Segundo Neri (2003), a rotação de 1.700 rpm está enquadrada na faixa de operação necessária para o transporte de madeira da empresa estudada, cujo consumo específico está na ordem de $193 \mathrm{~g} / \mathrm{kWh}$, com potência próximo da máxima e torque superior ao equivalente à potência máxima. Desta maneira, utilizou-se a equação 1 (Mialhe, 1996) para cálculo do consumo horário na rotação de $1.700 \mathrm{rpm}$, tendo sido encontrado o valor de $62,895 \mathrm{~L} /$ hora. Obteve-se então o consumo de combustível atribuído ao excesso de rpm do motor (acima de 2.000 rpm), utilizando nos cálculos o consumo na rotação de $2.000 \mathrm{rpm}$ e na faixa em que poderia ter sido realizado o trabalho, caso fosse respeitada uma dinâmica de condução do veículo, considerando a rotação de $1.700 \mathrm{rpm}$. Essa diferença de consumo foi de $0,1596 \mathrm{~L} /$ minuto, valor este considerado como desperdício, calculado para cada veículo.

\subsection{Marcha Lenta do Motor OM 457 LA}

De acordo com Neri (2003), o consumo de combustível do motor OM 457 LA do LS 2638 em marcha lenta é de $3 \mathrm{~L}$ de diesel por hora, sendo este valor utilizado nos cálculos em relação ao consumo de combustível para esta marcha.

\subsection{Ponto Neutro}

$\mathrm{O} \mathrm{MB}$ registrou as quantidades de ponto neutro ("banguelas") e seus respectivos tempos de duração nos dias de operação. O tempo gasto em ponto neutro foi considerado como rotação em marcha lenta, atribuída como desperdício, uma vez que não há consumo de combustível para estes veículos, caso permaneçam com freio do motor acionado.

\subsection{Análise dos Dados}

Foi utilizada a estatística descritiva na análise dos dados, uma vez que se trabalhou com todos os veículos que tinham computador de bordo instalado.

\section{RESULTADOS E DISCUSSÃO}

\subsection{Dispêndio Mensal com Combustível}

A dinâmica de condução dos veículos das transportadoras A e B pode ser constatada com a distribuição do custo mensal (R $\$ / m e ̂ s)$ correspondente ao consumo de combustível, apresentado na Figura 4, em que se utilizou o valor de R \$ 0,9524, para o combustível, média dos meses de setembro a novembro de 2002.

No Quadro 1 estão os valores médios do gasto mensal com combustível, referentes aos parâmetros marcha lenta, excesso de rotação e ponto neutro, para as transportadoras A e B. O maior desperdício de combustível está associado ao funcionamento do motor em marcha lenta: 91,32 e $99,09 \%$, respectivamente, para as transportadoras A e B. Os relatórios fornecidos pelos
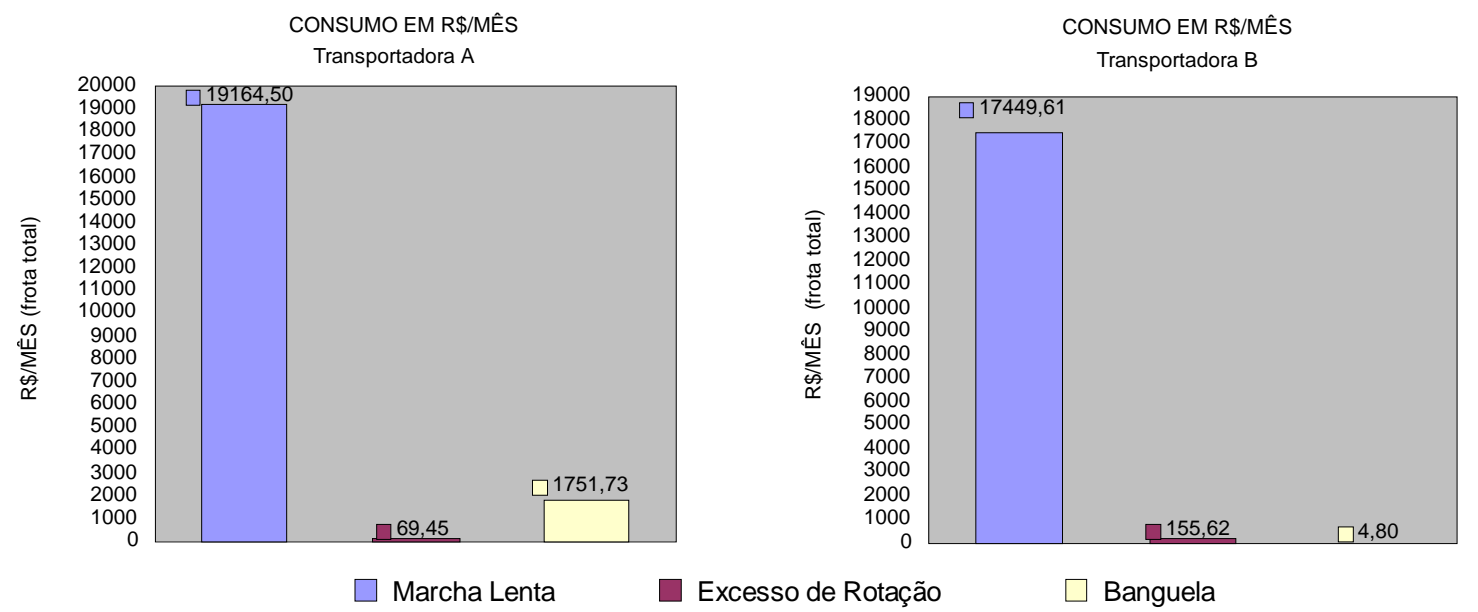

Figura 4 - Distribuição dos custos mensais de combustível.

Figure 4 - Monthly fuel costs distribution.

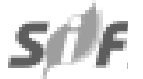

R. Árvore, Viçosa-MG, v.28, n.1, p.99-106, 2004 
Quadro 1 - Valores médios mensais de dispêndio com combustível Table 1 - Monthly average values of fuel expenditure

\begin{tabular}{|c|c|c|c|c|}
\hline \multirow{2}{*}{ Transportadora A } & Marcha Lenta* & Excesso de Rotação & Ponto Neutro & \multirow{2}{*}{$\begin{array}{c}\text { Total Geral } \\
\text { (frota/mês) }\end{array}$} \\
\hline & \multicolumn{3}{|c|}{ (R\$/mês) } & \\
\hline Média & $361,59^{1 /}$ & 1,29 & 32,44 & \\
\hline Erro-Padrão da Média & 11,49 & 0,31 & 22,03 & \\
\hline Total (frota) & $19.164,50$ & 69,45 & $1.751,73$ & $20.985,68$ \\
\hline$\%$ de consumo & 91,32 & 0,33 & 8,35 & 100,00 \\
\hline \multirow{2}{*}{ Transportadora B } & Marcha Lenta** & Excesso de Rotação & Ponto Neutro & Total Geral \\
\hline & \multicolumn{3}{|c|}{$(\mathrm{R} \$ / \mathrm{mês})$} & (frota/mês) \\
\hline Média & 436,24 & 3,89 & 0,12 & \\
\hline Erro-Padrão da Média & 25,16 & 1,07 & 0,02 & \\
\hline Total (frota) & $17.440,61$ & 155,62 & 4,80 & $17.610,04$ \\
\hline$\%$ de consumo & 99,09 & 0,88 & 0,03 & 100,00 \\
\hline
\end{tabular}

$*$ Porcentual médio do motor funcionando em marcha lenta $=24,47$; e ** Porcentual médio do motor funcionando em marcha lenta $=25,79$.

1/ Este valor médio refere-se a uma população de 53 caminhões.

computadores de bordo revelaram valor porcentual médio de funcionamento do motor em marcha lenta de $24,47 \%$ para a transportadora A e de $25,79 \%$ para a transportadora B. Esse valor é elevado quando comparado à média do tempo do motor funcionando em marcha lenta, de 5\%, obtida de cinco transportadoras de cargas diversas, referente a veículos pesados, após estarem cientes do funcionamento do sistema MB (AEROELETRÔNICA, 2003).

Considerando como padrão de funcionamento do motor em marcha lenta o tempo médio de 5\%, uma vez que é possível obter este valor ao desligar o motor durante as paradas que despendem maior tempo, pode-se reduzir o seu funcionamento nesta marcha em 19,47 e 20,79\%, respectivamente, para as transportadoras $\mathrm{A}$ e $\mathrm{B}$, resultando em uma economia, em relação ao parâmetro marcha lenta, de $79,57 \%$ para a transportadora A e de $80,61 \%$ para a transportadora B.

Existem para esse parâmetro agravantes que não foram analisados, mas que são conhecidos. Um exemplo é o maior desgaste do motor devido à queima parcial do combustível, ocasionando maior acúmulo de resíduos, que são levados para o cárter e contaminam o óleo do motor (Neri, 2003).

Ainda de acordo com o Quadro 1, o excesso de rotação representou 0,33 e $0,88 \%$ dos gastos referentes aos parâmetros analisados para as transportadoras A e
B, respectivamente. Sua média foi de $\mathrm{R} \$ 1,29$ ao mês para a transportadora A e de $\mathrm{R} \$ 3,89$ para a transportadora $\mathrm{B}$. $O$ custo mensal da frota foi de $\mathrm{R} \$ 69,45$ para a transportadora A e de 155,62 para a transportadora B. Uma análise mais detalhada das informações apresentadas no relatório do $\mathrm{MB}$, referente ao excesso de rotação, mostrou que, para a transportadora $\mathrm{B}$, oito equipes cometeram entre 600 e 3.200 excessos de rotação ao mês, representando $68,55 \%$ do total gasto em reais por mês para esta frota. Considerando que o valor configurado como excesso era quando a rotação do motor excedia a $2.000 \mathrm{rpm}$, pois segundo o instrutor da Mercedes-Benz o transporte na empresa estudada pode ser realizado com rotação de $1.700 \mathrm{rpm}$, fica claro que valores superiores a esta rotação não são justificáveis e causam gasto desnecessário com combustível, motor, peças e mecanismos que o compõem, que são mais rapidamente deteriorados pela freqüente permanência de uma rotação muito elevada.

A análise do ponto neutro dos veículos de ambas as transportadoras apresentou, respectivamente, $8,35 \mathrm{e}$ $0,03 \%$ do custo associado ao consumo de combustível, em relação aos parâmetros estudados. Uma análise individual de cada veículo da transportadora A revelou que a grande maioria das equipes não comete a infração, ou a cometeu em pequeno número, mostrando que das 54 equipes analisadas três apresentaram valores entre 800 e 6.100 pontos neutros por mês e foram responsáveis por $96,91 \%$ do total gasto em reais pela frota. A 
transportadora A apresentou média de $\mathrm{R} \$ 32,44$, totalizando um gasto de $\mathrm{R} \$ 1.751,73$ mensal, ou de $\mathrm{R} \$ 21.020,76$ ao ano para toda a frota. Já a transportadora B apresentou média de $\mathrm{R} \$ 0,12$ e gasto mensal de $\mathrm{R} \$ 4,80$ ou $\mathrm{R} \$ 57,60$ ao ano, valores bem menores que os da outra transportadora. As considerações deste parâmetro, no que se refere ao desgaste do motor, são as mesmas da marcha lenta. Um fator de extrema relevância é em relação à segurança, uma vez que esses veículos podem perder o controle e causar acidentes.

\subsection{Consumo}

Nesta análise, diferentemente da anterior, os dados foram representados em L/mês, e não em reais por mês. Esta análise é importante, uma vez que podem ser feitas simulações com diferentes valores do combustível, já que seus preços são constantemente modificados. $\mathrm{O}$ Quadro 2 apresenta os valores de consumo médio (L/mês) referentes aos parâmetros marcha lenta, excesso de rotação e ponto neutro, para a frota de veículos das transportadoras A e B.

A marcha lenta apresentou, para ambas as transportadoras, o maior consumo de combustível entre os parâmetros analisados. A transportadora A consumiu 20.122,33 L/mês e a transportadora B, 18.321,72 L/mês (Quadro 2). O consumo referente ao tempo de funcionamento do motor excedendo rotação apresentou valor pouco expressivo para ambas as transportadoras, sendo a transportadora A responsável pelo consumo de $72,92 \mathrm{~L} / \mathrm{mês}$ e a transportadora B por 163,4 L/mês. Esse valor poderia ser maior, caso fossem configurados para o computador de bordo, como excesso de rotação, valores acima de 1.700 rpm - que é a rotação ideal para realizar o transporte de madeira nas condições de estudo, segundo Neri (2003), devido à predominância de uma geometria plana das estradas, em vez de $2.000 \mathrm{rpm}$. É importante salientar que este número, trabalhado nos cálculos de consumo de combustível, compreende a um valor mínimo da infração e não a um valor médio.

Para o ponto neutro, o consumo atribuído foi de 1.839,28 L/mês para a frota da transportadora A, valor mais alto, devido a três equipes que não seguiram uma conduta adequada na forma de dirigir, afetando o consumo e comprometendo a segurança. No caso da transportadora $\mathrm{B}$, foi registrado um consumo de 5,04 L/mês para a frota (Quadro 2).

\subsection{Infrações}

As ocorrências de infrações estão apresentadas no Quadro 3. O excesso de rotação apresentou média de ocorrência de 126,32 por mês para a transportadora A e de 409,38 para a transportadora B. A primeira cometeu 6.821,35 excessos por mês e a segunda, 16.375; nesta última, oito equipes apresentaram entre $600 \mathrm{e}$ 3.200 excessos de rotação por mês, que representou $64,48 \%$ do total cometido pela frota ao mês. A conseqüência disso, embora não quantificada, é o maior desgaste de peças e mecanismos do conjunto, principalmente do motor, comprometendo assim a duração de sua vida útil.

Quadro 2 - Valores médios de consumo mensal de combustível Table 2 - Monthly average values of fuel consumption

\begin{tabular}{|c|c|c|c|c|}
\hline \multirow{2}{*}{ Transportadora A } & Marcha Lenta* & Excesso de Rotação & Ponto Neutro & Total Geral \\
\hline & \multicolumn{3}{|c|}{$(\mathrm{R} \$ / \mathrm{mês})$} & (frota/mês) \\
\hline Média & $379,67^{1 / \prime}$ & 1,35 & 34,06 & \\
\hline Erro-Padrão da Média & 12,06 & 0,32 & 23,14 & \\
\hline Total (frota) & $20.122,33$ & 72,92 & $1.839,28$ & $22.034,53$ \\
\hline \multirow{2}{*}{ Transportadora B } & Marcha Lenta** & Excesso de Rotação & Ponto Neutro & Total Geral \\
\hline & \multicolumn{3}{|c|}{ (R\$/mês) } & (frota/mês) \\
\hline Média & 458,04 & 4,09 & 0,13 & \\
\hline Erro-Padrão da Média & 26,42 & 1,13 & 0,03 & \\
\hline Total (frota) & $18.321,72$ & 163,40 & 5,04 & $18.490,17$ \\
\hline
\end{tabular}

$*$ Porcentual médio do motor funcionando em marcha lenta $=24,47$; e ** Porcentual médio do motor funcionando em marcha lenta $=25,79$.

${ }^{1 /}$ Este valor médio refere-se a uma população de 53 caminhões. 
Quadro 3 - Valores médios de infrações Table 3 - Average driving violation values

\begin{tabular}{|l|r|r|r|}
\hline \multirow{2}{*}{ Transportadora A } & $\begin{array}{c}\text { Excesso de } \\
\text { Rotação } \\
(>2.000 \mathrm{rpm})\end{array}$ & Ponto Neutro & Velocidade \\
\cline { 2 - 4 } & \multicolumn{3}{|c|}{ (quantidade/mês) } \\
\hline Média & 126,32 & 197,38 & 229,91 \\
\hline Erro-Padrão da Média & 25,80 & 124,68 & 107,27 \\
\hline Total (frota) & $6.821,35$ & $10.658,77$ & $12.415,26$ \\
\hline Transportadora B & & & 0,13 \\
\hline Média & 458,04 & 4,09 & 0,13 \\
\hline Erro-Padrão da Média & 92,18 & 1,63 & 89,72 \\
\hline Total (frota) & $16.375,00$ & 340,79 & $7.289,07$ \\
\hline
\end{tabular}

O ponto neutro apresentou média de 197,38 e 8,52 ocorrências por mês para as transportadoras A e B, respectivamente. A primeira registrou $10.658,77$ ocorrências por mês para toda a frota e a segunda, apenas 340,79 (Quadro 3), valor este pequeno, embora expressivo, tanto em desperdício de combustível e desgaste do motor, como no aumento do risco com a segurança. Em análise minuciosa dos dados constatou-se que o valor médio da transportadora $\mathrm{A}$ foi devido a três equipes, que ignoraram a forma econômica e segura de condução do veículo e apresentaram entre 800 e 6.100 ocorrências por mês, responsáveis por $94,39 \%$ do total de ocorrências de pontos neutros da frota no mês.

A velocidade teve ocorrência média de 229,91 vezes por mês para a transportadora A e 182,23 para a transportadora B. Analisando os dados, constata-se que a média da transportadora A foi influenciada por quatro equipes, que cometeram entre 500 e 4.000 infrações por mês e foram responsáveis por $86,3 \%$ da quantidade total de infrações cometidas pela frota no mês. $\mathrm{O}$ mesmo ocorreu com a transportadora $\mathrm{B}$, sob influência também de quatro equipes, que cometeram entre 400 e 3.700 infrações de velocidade por mês, representando $71,29 \%$ do total de infrações cometidas pela frota ao mês. A transportadora A apresentou 12.415,26 ocorrências por mês para toda a frota e a transportadora B, 7.289,07, alertando para uma maior preocupação com o consumo de combustível, a segurança e as inúmeras conseqüências que possam surgir caso ocorram acidentes.

\section{CONCLUSÕES}

- A marcha lenta foi responsável pelo maior desperdício de combustível no transporte de madeira, seguida do ponto neutro e do excesso de rotação.
- No transporte de madeira é possível reduzir drasticamente o desperdício de combustível causado pelo uso da marcha lenta, se houver uma racionalização do tempo de espera.

- O uso do ponto neutro ("banguela") e do excesso de velocidade nos veículos não economiza combustível, mas compromete a segurança.

- Um baixo número de equipes foi responsável pelo elevado número de infrações cometidas.

- A falta de treinamento dos motoristas contribuiu para o aumento do consumo de combustível.

\section{REFERÊNCIAS BIBLIOGRÁFICAS}

AEROELETRÔNICA. Introdução. Porto Alegre, 2003. $12 \mathrm{p}$.

AEROELETRÔNICA. Manual de operação do sistema MB. Porto Alegre, 1997. $65 \mathrm{p}$.

BARROS, L. F. Densidade do combustível. Aracruz: Aracruz Celulose, 2003. (Informação Verbal).

BIOCHINI, H. D. Mais eficiência no uso de combustível. Revista Transporte Moderno, n. 399, p. 51-52, 2002.

DEWELT, R. L. Control: key to making strategy work. Management Review, 1977. p. 18.

GUIMARÃES, N. V. Reduzindo o consumo.

Disponível em: <http://www.revistaocarreteiro.com.br/ ano2000/Edicao316/frota.htm>. Acesso em: 28 mar. 2003.

MACHADO, C. C.; LOPES, E. S.; BIRRO, M. H. B. Elementos básicos do transporte florestal rodoviário. Viçosa: Universidade Federal de Viçosa, 2000. 167 p.

MERCEDES-BENZ. Disponível em: <http:// www.mercedes-benz.com.br/veiculos_comerciais/ caminhoes/extrapesados_ls2638.htm01/02/03>. Acesso em: 01 fev. 2003.

MIALHE, L. G. Máquinas agrícolas: ensaios \& certificação. Piracicaba, SP: Shekinah, 1996. 722 p.

NERI, L. Consumo de combustível. Aracruz: Aracruz Celulose, 2003. (Informação verbal).

ROCHA, L. O. L. Organização e métodos: uma abordagem prática. 6.ed. São Paulo: Atlas, 1995. 286 p.

THOMPSON, A. How to share control. Management Today, v. 9, p. 71, 1976. 